\title{
SONHAR GRUPAL: UMA PROPOSTA PARA O TRABALHO COM SONHOS EM GRUPO
}

\author{
Pablo Castanho \\ Universidade de São Paulo, São Paulo-SP, Brasil \\ Solange Aparecida Emílio \\ Núcleo de Estudos em Saúde Mental e Psicanálise das Configurações Vinculares, São Paulo-SP, Brasil \\ Victória de Angelis \\ Wellington Gomes da Silva \\ Mayara Coutinho \\ Universidade de São Paulo, São Paulo-SP, Brasil
}

\begin{abstract}
RESUMO
Este estudo apresenta o Sonhar Grupal, um dispositivo de trabalho com sonhos em grupos, criado por um grupo de pesquisa brasileiro e inspirado na Matriz do Sonhar Social, técnica desenvolvida por pesquisadores do Tavistok Institute, em Londres. O Sonhar Grupal apresenta, no entanto, diferenças e especificidades: uma concepção psicanalítica intersubjetiva do sonhar, a consideração do grupo e seus processos específicos, o relato do sonho como objeto mediador e a perspectiva de um grupo centrado em uma tarefa que pode ser adaptada para diferentes contextos. São trazidas ilustrações e discussões sobre suas aplicações, manejo e possíveis efeitos, com a expectativa de que seu uso possa ser ampliado como estratégia de promoção de saúde mental para um número expressivo de pessoas.
\end{abstract}

Palavras-chave: grupos; sonhos; Psicanálise.

\section{GROUP DREAMING: A PROPOSAL FOR WORKING WITH DREAMS IN GROUPS}

\section{Abstract}

This paper presents the Group Dreaming, a method for working with dreams in groups, created by a Brazilian research group and inspired by the Social Dreaming Matrix, a technique developed by researchers at the Tavistok Institute in London. The Group Dreaming presents, however, differences and specificities: an intersubjective psychoanalytic conception of dreaming, the consideration of the group and its specific processes, the dream report as a mediating object and the perspective of a task centered group that can be adapted to different contexts. It will provide examples and discussions about its uses, conduction and possible effects, with the expectation that it can be expanded as a strategy to promote mental health for a significant number of people.

Keywords: groups; dreaming; Psychoanalysis. 


\section{SOÑAR EN GRUPO: UNA PROPUESTA PARA TRABAJAR CON LOS SUEÑOS EN GRUPO}

\section{RESUMEN}

Este artículo presenta el Soñar Grupal, un método de trabajo con los sueños en grupos, creado por un grupo de investigación brasileño e inspirado en la Matriz del Sueño Social, técnica desarrollada por investigadores del Instituto Tavistok de Londres. El Soñar Grupal presenta, sin embargo, diferencias y especificidades: una concepción psicoanalítica intersubjetiva del sueño, la consideración del grupo y sus procesos específicos, el informe del sueño como objeto mediador y la perspectiva de un grupo centrado en una tarea que puede adaptarse a diferentes contextos. Se ofrecerán ejemplos y discusiones sobre sus usos, conducción y posibles efectos, con la expectativa de que pueda ampliarse como estrategia para promover la salud mental de un número importante de personas.

Palabras clave: grupos; sueños; Psicoanálisis.

\section{O SONHO NOS GRUPOS E O SONHAR GRUPAL}

O Sonhar Grupal é nome de um dispositivo de trabalho com sonhos em grupos criado a partir de uma releitura e apropriação particular da Matriz de Sonhar Social. Esta foi originalmente desenvolvida por Gordon Lawrence e colaboradores no Tavistok Institute, em Londres (Lawrence, 1998).

O desenvolvimento do Sonhar Grupal ocorreu ao longo dos anos de 2020 e 2021 e contou com a participação de integrantes do CLIGIAP (Clínica de Grupos e Instituições na Abordagem Psicanalítica), grupo de pesquisa cadastrado no CNPq e vinculado ao LIPSIC (Laboratório de Estudos da Intersubjetividade e da Psicanálise Contemporânea - USP/PUC), que buscavam uma forma de cuidado em grupos para os psicólogos que realizavam atendimentos clínicos voluntários aos membros da comunidade USP, pelo Projeto de Apoio Psicológico Online do IPUSP (PAPO), visando ao auxílio no enfrentamento das dificuldades psicológicas desencadeadas pela pandemia de COVID-19. Os psicólogos voluntários do PAPO constituíam-se de docentes, estudantes de pós-graduação envolvidos em projetos de pesquisa e de extensão universitária e egressos de cursos do Instituto de Psicologia. Então, foi convidada a psicóloga, psicanalista e pesquisadora Carla Penna para contribuir no desenho de um dispositivo que pudesse ofertar este espaço de elaboração e compartilhamento entre os profissionais, pois ela já havia conduzido cursos e vivências sobre a Matriz do Sonhar Social com a participação de membros do grupo de pesquisa e é autora de um artigo considerado uma importante referência no país em relação ao tema (Penna, 2013).

Assim, nos meses de maio e junho de 2020, foram ofertados encontros semanais da Matriz do Sonhar Social, de forma remota, aos voluntários do referido projeto de atendimento, nos quais Carla Penna figurava como a anfitriã, tendo como co-anfitriões alguns dos autores deste artigo. Foram oito encontros abertos, com uma semana de intervalo entre eles, que tiveram 26 participantes, presentes em um ou mais encontros. 
A estrutura dos encontros era dividida em dois momentos: no primeiro eram relatados sonhos e associações e no segundo eram realizadas reflexões sobre os seus significados coletivos. Sempre que havia pessoas novas, a anfitriã informava um pouco sobre a origem do dispositivo e esclarecia o funcionamento de cada momento. Todos partilhavam sonhos, associações e reflexões, inclusive os anfitriões. Este foi percebido como um importante espaço de acolhimento aos profissionais, especialmente necessário pelo fato de que todos estavam imersos no mesmo contexto pandêmico e de luto dos clientes que estavam atendendo.

Outros pesquisadores brasileiros vinham, ao mesmo tempo, realizando estudos psicanalíticos com o enfoque no conteúdo dos sonhos ocorridos durante a Pandemia. Destacamos duas perspectivas de pesquisas evidenciadas em obras coletivas: uma organizada por Dunker, Perroni, Ianinni, Rosa e Gurski (2020), vertente marcadamente lacaniana e outra organizada por Pereira e Coelho Jr. (2021), obra plural, mas com forte presença da perspectiva ferencziana sobre os sonhos. Em um ambiente de interesse generalizado sobre o assunto registramos outros trabalhos como, por exemplo, os de Coutinho (2020) e Zerbatto e Prestes (2020). Apesar de realizados por diferentes grupos de trabalho, com perspectivas teóricas que se aproximam em alguns pontos e distanciam-se em outros, esses textos e as experiências na Matriz do Sonhar Social apresentavam como convergências a importância dada aos sonhos no atravessamento deste momento e a tentativa, por meio do contato com as narrativas e imagens dos sonhos, de compreensão das alterações psíquicas e sociais promovidas pela situação coletivamente enfrentada.

A participação nas experiências de Matriz do Sonhar Social foi articulada a outras intervenções em grupos que vinham sendo realizadas por alguns dos autores do presente artigo, como os grupos que intercalam encontros verbais aos mediados por fotos (Castanho, Emílio, Oliveira, \& Neves, 2020) e as sessões de

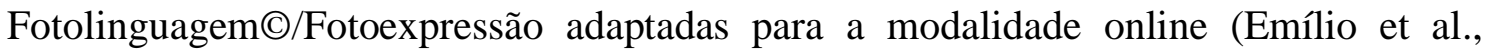
2020). Então, o trabalho com o relato dos sonhos como objetos mediadores passou a ser considerado nas intervenções que se seguiram.

Assim, já renomeado como "Sonhar Grupal", o dispositivo foi aplicado a outros grupos de profissionais do campo da Saúde. Vem sendo ofertado de forma semanal, desde novembro de 2020 até o momento da finalização deste artigo (novembro de 2021), à população geral, com acesso gratuito e online, constituindo, além de um espaço de promoção de saúde mental, um importante campo de prática supervisionada dentro do Programa Autoestima (promovido pela Secretaria Estadual de Saúde, em parceria com a USP, que tem oferecido, durante a pandemia, de forma online, cursos de aperfeiçoamento a profissionais da Rede de Atenção Psicossocial e atendimento individual e grupal à população).

O objetivo deste artigo é apresentar a técnica do Sonhar Grupal, diferenciando-a de outras modalidades de intervenção em grupo, trazendo ilustrações e discussões sobre suas aplicações e possíveis efeitos, com a expectativa de que seu uso possa ser ampliado como estratégia de promoção de saúde mental para um número expressivo de pessoas. Apesar da influência em sua origem e de algumas semelhanças com a Matriz do Sonhar Social que se mantêm, entendemos que o Sonhar Grupal apresenta como especificidades os quatro pontos que serão abordados neste artigo: uma concepção psicanalítica intersubjetiva do sonhar, a consideração do grupo e seus processos específicos, o relato 
do sonho como objeto mediador e a perspectiva de um grupo centrado em uma tarefa que pode ser adaptada para diferentes contextos.

\section{SOBRE UMA CONCEPÇÃO PSICANALÍTICA INTERSUBJETIVA DO SONHAR}

Vamos começar discriminando a Matriz do Sonhar Social e o Sonhar grupal no que diz respeito aos referenciais teóricos. Para pensar o fenômeno do sonho no grupo, Gordon Lawrence recorreu a múltiplas referências. Apesar de se apoiar em autores da Psicanálise como Bion, Winnicott e Bollas, também utilizou conhecimentos de outras áreas do saber, como a física quântica para explicar, por exemplo, o conceito de infinito e da conexão entre o que ocorre na Matriz do Sonhar Social como algo que remete ao universal (Manley, 2014; Penna, 2013).

Além disto, sublinhamos a influência do livro "Sonhos no terceiro Reich" (Beradt, 1966/2017) no pensamento de Lawrence e como ele estabelece uma conexão direta entre o sonho e o mundo social e político. Todos estes elementos fazem com que os fenômenos intersubjetivos de grupo sejam desconsiderados quando o enfoque é na Matriz do Sonhar Social. Já a releitura para o Sonhar Grupal remonta a uma fundamentação estritamente psicanalítica do sonho em grupo, notadamente com a perspectiva da polifonia do sonho em René Kaës (2002), tendo estreita relação com a intersubjetividade e, portanto, permitindo afirmar o grupo como categoria central no trabalho com sonhos.

O fenômeno dos sonhos na perspectiva intersubjetiva é pensado pelo próprio Kaës (2003) sob diversos ângulos, por exemplo, ao abordar os sonhos do analista com o analisando e os sonhos do analista que ocorrem em sessão (mediante um cochilo), e ao trazer obras da literatura acerca dos sonhos. Desta forma, Kaës propõe que, tal qual para Freud existe um "umbigo do sonho" no âmbito do somático, também existe um "umbigo do sonho" no âmbito intersubjetivo, ou seja, há algo que, nos sonhos, é nutrido da intersubjetividade e que se apresenta com essa significação de uma dimensão também vincular. Assim, mesmo quando se trata do sonho de um indivíduo, há uma combinação de várias vozes, uma polifonia, a criação de um espaço onírico comum e compartilhado. O autor cita Gordon Lawrence, localizando sua contribuição no que denomina "terceiro umbigo do sonho", que remete à dimensão social. Notemos que por este mesmo movimento sinaliza a distância dos autores em relação à problemática da intersubjetividade e, portanto, do grupo.

\section{O GRUPO E SEUS PROCESSOS ESPECÍFICOS}

Uma diferença bastante importante entre os dois dispositivos aqui discutidos está no enfoque na matriz, no caso do Sonhar Social, e no grupo, quando considerado o Sonhar Grupal.

Lawrence (2010) deixa clara sua opção por não trabalhar com o conceito de grupo, pois pretende recriar na Matriz do Sonhar Social a indiferenciação inconsciente da vida onírica e constituir, com inspiração no uso comum do termo "matriz", um lugar que permita o crescimento de emoções e sentimentos presentes na vida social. $\mathrm{O}$ enfoque está nos sonhos narrados e não nos sonhadores ou suas relações, uma vez que, 
para o autor, os sonhos ampliam o espaço do possível. No contexto do Sonhar Social, Lawrence (2010) prefere as concepções de infinito e finito às de consciente e inconsciente e define o infinito como um espaço mental contido em nossos mundos internos no qual está tudo o que foi pensado ou poderá ser pensado.

A matriz é tida como o espaço a partir do qual tudo o que existe teve origem e, portanto, precede à invenção dos grupos pela humanidade. Assim, a Matriz do Sonhar Social promoveria a possibilidade de transcendência em direção ao infinito. A organização das pessoas na atividade quando feita de forma presencial é pensada para promover anonimato e garantir o princípio de que o sonho partilhado é social e não pessoal (Lawrence, 2010). A organização das cadeiras em formato de "floco de neve" é escolhida para que os participantes não fiquem face a face e para que seja rompido o padrão de interação usual em grupos (Gui \& Coelho, 2014; Manley, 2014). Assim, na Matriz do Sonhar Social, o grande agrupamento de até 60 pessoas se constitui de pessoas organizadas de quatro em quatro, que ficam sentadas de costas umas para as outras (Hazan, Knobel, \& Fernandes, 2014). A atividade é conduzida por anfitriões, denominados assim por serem responsáveis pela recepção e acolhimento aos participantes e aos seus sonhos.

Na Matriz do Sonhar Social (Gui \& Coelho, 2014; Hazan et al., 2014; Manley, 2014; Penna, 2013), podemos convidar as pessoas a, em um primeiro momento, contar sonhos e associar sobre eles e, em um segundo momento, refletir sobre o significado coletivo desses sonhos. Esta divisão em dois momentos também está sempre presente no dispositivo do Sonhar Grupal que aqui apresentamos.

Como um recurso, o Sonhar Grupal, por sua vez, pode ser realizado com diferentes configurações e objetivos: tanto em grupos pontuais e abertos, quanto recorrentes com os mesmos participantes; em grupos grandes, médios ou pequenos; em grupos terapêuticos ou com outras finalidades. Pode ser feita uma oficina de Sonhar Grupal com repetidas sessões apenas sobre sonhos. Ou, ainda, ocorrer uma única sessão, como uma atividade pontual em um grupo terapêutico já existente, para lidar com problemas que tenham surgido no grupo.

Isso abre o horizonte para uma demanda nova: trabalhar alguns fenômenos que não podem ser desconsiderados nos formatos em que as pessoas estabelecem um contato mais prolongado. Mesmo no caso de contatos pontuais, ainda há uma distinção, já que é usado o ferramental das teorias psicanalíticas de grupo para compreender e operar sobre o que se passa no grupo.

Em função do papel esperado ao(s) anfitrião(ões) da Matriz do Sonhar Social, a questão transferencial não é considerada no dispositivo (Manley, 2014; Penna, 2013). Em contraste, no Sonhar Grupal tais fenômenos adquirem importância e demandam que sejam considerados. Quando há pessoas cujas presenças nas sessões é recorrente, na medida em que estas começam a se conhecer, passam não apenas a ter representações mútuas sobre quem é quem e sobre as possíveis reações do outro, como também a sonhar para o grupo e para seus componentes. A participação no Sonhar Grupal estimula uma maior percepção e lembrança sobre os próprios sonhos, os quais, muitas vezes, acabam sendo endereçados aos demais participantes do grupo. Como veremos adiante, a cadeia associativa grupal operará tanto no relato dos sonhos como nas associações trazidas.

Ao utilizarmos o termo grupo, queremos evocar todo o arsenal teórico das teorias psicanalíticas de grupo que poderiam então ser colocados a serviço do manejo do 
dispositivo de sonhar grupal. Entretanto, a literatura nos aponta a existência de distintos dispositivos de grupo com impactos importantes sobre a forma de leitura e de seu manejo. É neste ponto que as duas próximas categorias são fundamentais ao organizarem o modo no qual vemos a inserção do sonhar grupal no campo das teorias psicanalíticas de grupo.

\section{O SONHO COMO OBJETO MEDIADOR}

Um grupo que compartilha e reflete sobre sonhos aproxima-se daquilo que na literatura francesa é trabalhado como grupos com objetos mediadores. Conceitos como "objeto mediador", "mediação terapêutica" e "meio maleável", dentre outros, remetemnos, originalmente, à apropriação francesa do psicodrama pelas teorias psicanalíticas de grupo desde os anos 1950 e, mais recentemente (basicamente desde a década de 1990), a uma tradição desenvolvida na Université Lumière Lyon 2, na França, da qual destacamos duas principais escolas que têm pensado tal questão (de certa forma conectadas entre si) além de um pensador independente, Bernard Chouvier (2004), que tem uma trajetória própria e criativa, mas que, de algum modo, circula entre ambas as perspectivas.

A primeira escola tem como protagonistas René Kaës e Claudine Vacheret, que privilegiam o estudo da articulação entre o objeto mediador e as condições intersubjetivas grupais a fim de favorecer a atividade representacional. Para Kaës (2005), do ponto de vista psíquico, pode ser importante o uso de uma "prótese" (que seriam os grupos mediados por objetos) naqueles casos em que se encontra "em pane" a capacidade de sonhar - no sentido amplo -, de associar ou de formar sintomas - no sentido freudiano. Tal como o autor aponta (Käes, 2005), essa área de estudos surgiu a partir da atuação de trabalhadores da linha de frente, sobretudo em saúde mental (por exemplo, nos hospitais-dia franceses), os quais, por um processo de tentativa e erro, foram inventando técnicas de trabalho em grupo (normalmente chamadas de oficina entre nós) com diferentes recursos e cujos resultados foram revelando-se expressivos.

Em um certo momento, Kaës, juntamente com colegas e sua equipe, começaram a estudar uma modelização que procurava compreender, sob o ponto de vista psicanalítico, o que se passa em tais técnicas de grupo. Foram propondo, assim, a ideia de que a condição-base de funcionamento do processo primário (Freud, 1900/1987) carrega uma dimensão intersubjetiva, além da noção de que haveria uma sinergia disso com a sensorialidade implicada pelo uso de objetos para favorecer a retomada do funcionamento do processo primário (Vacheret, 2000, 2008).

Esta temática é bastante explorada na Fotolinguagem $(\mathcal{C}$, técnica de trabalho com grupo que utiliza fotos como objeto mediador. Claudine Vacheret, cujas ideias também influenciaram o presente artigo, participou da criação desta técnica. A Fotolinguagem $($, que foi originalmente pensada para uso com adolescentes, passou a ser aplicada, com adultos em empresas e no campo psicossocial (Vacheret, 2008). Mas, a partir da abordagem psicanalítica proposta por Vacheret, esta encontrou espaço no campo da saúde mental - sobretudo com pacientes psicossomatizadores - e com uma série de outros usos clínicos. Para Castanho (2008), a proposta de Claudine Vacheret para a Fotolinguagem(@ permite que esta seja tomada como situação de referência para o uso de outros objetos mediadores em grupo. 
No contexto francês, a discussão sobre objetos mediadores aparece muito ligada a patologias mais graves, que também podem ser pensadas sob a ordem do traumático isto é, patologias em que a ruptura psíquica deixou marcas muito significativas na constituição e funcionamento psíquicos do sujeito. Além disso, há elementos na literatura para defendermos que a categoria do traumático em sua dimensão social também demanda e se beneficia de intervenções com o uso de objetos mediadores. Chamamos aqui especial atenção para um texto de René Kaës (2005) que trata de uma intervenção com o psicodrama psicanalítico de grupo, na cidade do México, em que se acredita que foram postos em trabalho aspectos relacionados a um grande terremoto que havia ocorrido no local.

Em todos esses casos, o uso de objetos em grupo busca o relançar da capacidade associativa. Assim, estamos no campo de uma leitura psicanalítica na qual a figura da interpretação adquire menor importância. Apesar de a interpretação poder ocorrer em algumas situações, o foco é no restabelecimento do funcionamento dinâmico do processo primário. Trata-se essencialmente de resgatar as capacidades de fantasiar, associar e sonhar, conforme a nomenclatura de preferência de cada analista.

Além da influência específica da pandemia, há uma discussão sobre o mal-estar na contemporaneidade em que vemos um crescimento de patologias associadas à pane no poder associativo. Por essas duas razões, o mal-estar na contemporaneidade e a dimensão da pandemia de COVID-19 como algo da ordem do traumático, o uso de objetos em grupos revela-se como extremamente interessante.

Caracterizamos a segunda escola de Lion pelas contribuições estruturantes de René Roussillon e Anne Brun. Roussillon (2013) resgata a ideia de meio maleável, da psicanalista Marion Milner, relacionando-o ao que chamam de processo de simbolização, e que entendemos como muito próximo ao problema da atividade representacional mencionada nos parágrafos anteriores. Os dois autores aprofundam o entendimento sobre como as características sensoriais de cada objeto mediador atuam no psiquismo. Eles constroem uma teorização muito interessante para entendermos por que uma pessoa se dá melhor com um objeto mediador e outra com outros objetos e, também, permitem-nos clarificar do ponto de vista técnico alguns elementos importantes sobre o manejo e o uso deste objeto. O conceito de "associatividade sensório motora" de Anne Brun (2013) é especialmente rico ao manejo dos grupos com objetos, afinando nossa escuta para as cadeias associativas que se desenvolvem encadeando percepções distintas, como as imagens, sentimentos e sensações corporais que surgem no Sonhar Grupal.

Ao tomarmos o sonho como objeto mediador, partimos do entendimento de que, primeiro, há algo da ordem do traumático e da dificuldade de simbolização; e segundo, estamos apostando que a base do trabalho é fazer um estímulo ao processo associativo, visando que surjam e se multipliquem imagens. É exemplar desta perspectiva quando pessoas voltam ao grupo em semanas seguintes relatando estarem sonhando mais ou lembrando-se mais de seus sonhos, ou quando pessoas dizem no início da sessão que não têm sonhado, porém, acabam recordando sonhos inteiros ou fragmentos $\mathrm{e}$ associações durante a própria sessão, conforme escutam os sonhos relatados pelos demais participantes.

Podemos, ainda, dar um passo além. No segundo momento do Sonhar Grupal cabem algumas interpretações de entendimento e de ligação entre essas produções oníricas com os eventos da vida. Entretanto, há de se ter cuidado, porque se a 
interpretação vier cedo demais pode bloquear o processo associativo. Um fenômeno muito interessante que tem surgido é a lembrança, nesse segundo momento, pelos coordenadores ou demais participantes, de músicas, filmes ou cenas, que são trazidas ao grupo como associações e que muitas vezes ajudam a fazer a necessária conexão entre os sonhos relatados e o que está sendo vivenciado pelos participantes do grupo no momento histórico e social, para possível elaboração.

Para exemplificar, trazemos uma sequência de associações surgidas em uma sessão de Sonhar Grupal, realizada no início do mês de março de 2021. No primeiro momento, foram compartilhados sonhos e associações com pessoas e animais mortos e abandonados, lama e coisas escorrendo, fraudes, projetos interrompidos, pessoas à beira de um precipício e expondo-se a riscos desnecessários. O clima no grupo parecia tenso e repleto de angústia.

Foram, então, surgindo associações com trechos de músicas e de filmes, que traziam mais uma possibilidade de mediação para a abordagem dos temas que estavam presentes. O primeiro trecho trazido foi da música Panis et Circencis, de Gilberto Gil e Caetano Veloso: "mas as pessoas na sala de jantar/são ocupadas em nascer e morrer"; depois, foram lembradas duas músicas sem letras e bem conhecidas de todos: a que, no filme Tubarão, remete ao momento em que o animal vai atacar algum turista e a que toca quando a mais conhecida emissora do país vai apresentar um plantão para anunciar alguma tragédia.

O grupo associou os sonhos e as músicas ao fato de que naqueles dias, ao mesmo tempo em que a vacinação avançava, alimentando a esperança de tempos melhores, também circulavam notícias aterradoras de profissionais que somente fingiam aplicar a vacina. Além disso, o número de mortes no país voltava a aumentar. Assim, foi possível a abordagem às incertezas que nos rodeavam e eram pioradas em função da polarização política em torno da questão de vacinar ou não as pessoas e das condições tão desiguais que determinavam as possibilidades de vida ou de morte (por um lado, os que podiam se vacinar, os que faziam trabalho remoto e os que estavam empregados; por outro, os que ainda não estavam autorizados a se vacinar, os desempregados ou que precisavam se colocar em situação de risco em função do trabalho). Foi lembrada a cena do filme "Parasita", na qual alguns são gratos pela chuva, enquanto outros estão afundados na enchente.

Muitas associações seguiram-se e foram lembrados os colegas de trabalho que haviam morrido pela COVID-19, em uma situação que "escorre pelas mãos", como na música "Tempos Modernos", de Lulu Santos. Mas, ao ser retomado o restante da letra desta música, "vamos viver tudo o que há pra viver/vamos nos permitir", puderam ser trazidos os sentimentos ambivalentes dos sobreviventes que também queriam poder se permitir viver e desfrutar dos encontros remotos como aqueles do Sonhar Grupal, que possibilitavam o compartilhamento das angústias e as conexões, mesmo em tempo de necessário isolamento social.

Existem diversas consequências em uma leitura do sonho como um objeto mediador. Uma delas é o cuidado de se dar importância ao trabalho com as imagens a todo tempo. A fala e o entendimento racional têm seu lugar no grupo, mas não podem substituir o lugar e a vivência do trabalho com as imagens. Uma outra consequência está em poder lidar com a agressividade. No Sonhar Grupal, os sujeitos estão sempre falando do sonho ou de suas imagens e não das pessoas que contam o sonho, e isso tem diversas implicações sobre o manejo. Quando um sonho está incomodando alguém, às vezes 
precisamos lembrar que não estamos falando das pessoas e que a ideia não deve se dirigir ao outro colega, mas ao sonho. Isso dá uma proteção quando os participantes estão com dificuldades de se relacionar. E esta, tem a ver, como temos podido verificar, com elementos da pandemia, elementos da modernidade, como visto no exemplo acima, com o cenário mais recente que afeta alguns lugares do mundo e a nós de modo bem claro, que é uma extrema polarização da sociedade.

\section{A POSSIBILIDADE DE DIFERENTES TAREFAS}

Chegamos, então, à noção de Tarefa proposta por Pichon-Riviére (1994/1980) que permite que o Sonhar Grupal seja desenvolvido para o trabalho em diferentes contextos. No caso, por exemplo, do grupo com psicólogos que atuavam como voluntários em um projeto de atendimento da universidade, a tarefa compreendia pensar o próprio trabalho a partir dos sonhos. Quando os participantes contavam os sonhos, sobretudo na fase reflexiva, sempre voltávamos ao assunto de seus trabalhos, abordando os sonhos como imagens que contam algo sobre como está sendo realizar esses atendimentos, da dificuldade e do cansaço, do receio com os outros e até questões das próprias instituições que estavam inseridos.

A tarefa explícita é apresentada no grupo no início da atividade ("estamos aqui para...") e entendemos que sua enunciação dispara conteúdos inconscientes aparentemente desconexos. Deve-se permitir que o grupo tenha tempo para associar sobre os conteúdos até que isso tome uma forma clara, quando, então, podemos propor alguma relação entre o que surgiu e a sua tarefa explícita (Castanho, 2017). Retomando os grupos aqui apresentados, podemos passar com eles um tempo discutindo questões aparentemente nada conectadas com sua prática profissional, mas quando deixamos as associações livres, alguma hora aquilo toma forma e podemos, no nosso caso, no segundo momento da sessão, propor ao grupo que há alguma relação com o que fazem profissionalmente. A tarefa não proíbe que sejam feitas associações, afinal, não afirmamos imperativos como "não saia do que eu propus". Nós propomos algo e vemos o que isso gera, às vezes sendo necessário esperar para que isso tome alguma forma e clareza para que possamos resgatar e falar.

Assim, há vários exemplos de tarefas que podem nortear o Sonhar Grupal, conforme os objetivos do grupo, como a intervenção em contextos organizacionais, educacionais e comunitários, além dos usos mais comuns no campo da saúde. Ao trabalharmos com o conceito de tarefa, é fundamental que ela fique clara aos participantes. Apresentamos, a seguir, as instruções que temos utilizado no Sonhar Grupal que vem sendo realizado semanalmente às quartas-feiras, das $19 \mathrm{~h}$ às $20 \mathrm{~h} 30$, pelo Google Meet, de forma gratuita e aberto à população geral, como parte das ações do Programa Autoestima:

Estamos aqui para realizar uma atividade de partilha de sonhos noturnos $e$ reflexão sobre os seus significados coletivos. Existem diferentes tipos de sonhos, neste grupo trabalharemos com aqueles sonhos que temos enquanto dormimos.

Este é um espaço aberto a todos os cidadãos interessados, de modo que se constitui em um espaço público. Como tal devemos zelar por ele. De fato, uma 
das propostas desta atividade é justamente fortalecemos vínculos pelo que nos une como pessoas, no respeito às diferenças e singularidades. Por isso é importante cuidarmos da forma como nos relacionamos no grupo, primando pelo respeito aos colegas tanto na forma como trazemos elementos ao grupo quanto da forma como reagimos ao que os outros trazem. Se a coordenação detectar algo que considere desrespeitoso, a pessoa será orientada e, em havendo reincidência, poderá ser removida.

A atividade é realizada em duas partes. Na primeira, todos são convidados a trazerem sonhos, fragmentos de sonhos e associarem sobre o que é trazido ao grupo. A partir do momento em que um sonho é trazido ao grupo, ele não é mais do sonhador, mas do grupo. Não precisam ser sonhos atuais, cada um pode trazer algum sonho que se lembre neste momento, mesmo que seja antigo.

Na segunda parte iremos refletir sobre o que estes sonhos e associações podem nos ajudar a compreender sobre a nossa experiência durante a pandemia. Refletiremos sobre o material compartilhado criando possibilidades de compreensão e significados.

A primeira parte vai até por volta de $19 h 55$ e a segunda parte termina às $20 h 30$.

\section{CONSIDERAÇÕES FINAIS}

Consideramos que a abordagem proposta pelo Sonhar Grupal pode ser uma valiosa aliada no enfrentamento de situações coletivas que aproveitem as bases intersubjetivas para o funcionamento do processo associativo, como a vivência da pandemia, sendo particularmente interessante seu uso comunitário pela possibilidade de atendimento de um número grande de participantes, flexibilidade para intervenções em diferentes contextos pelo ajuste da tarefa específica e boa adequação para a realização de forma remota.

\section{REFERÊNCIAS}

Beradt, C. (2017). Sonhos no Terceiro Rech: com o que sonhavam os alemães depois da ascensão de Hitler. Três Estrelas. (Original publicado em 1966).

Brun, A. (2013). Spécificité de la symbolisation dans les médiations. In A. Brun, B. Chouvier \& R. Roussillon, Manuel des médiations thérapeutiques. (pp. 122-158). Dunod. https://doi.org/10.3917/dunod.chouv.2013.01.0122

Castanho, P. (2008). A Fotolinguagem (C: uma situação de referência para o trabalho de orientação psicanalítica com grupos que utilizam a mediação de objetos. Psicologia: Teoria e Prática, 10, p. 192-201.

Castanho, P. (2017). Sobre a questão da tarefa no grupo: aspectos psicanalíticos e psicossociais. In M. Y. Okamoto \& T. S. Emídio (Orgs.), Perspectivas psicanalíticas atuais para o trabalho com grupos e famílias na Universidade (pp. 88-101). Cultura Acadêmica. 
Castanho, P., Emílio, S. A., Oliveira, K. C. S., \& Neves, P. H. (2020). Grupo Reflexivo de Apoio à Permanência da Universidade de São Paulo (GRAPUSP): uma estratégia de cuidado aos estudantes e sua adaptação ao contexto on-line. In K. C. Nascimento, \& M. B. Sei (Orgs.), Intervenções psicológicas on-line: reflexões e retrato de ações (pp. 116-135). Clínica Psicológica da UEL.

Coutinho, B. (2020). A psicanálise dos sonhos durante a pandemia. Revista Brasileira de Psicanálise, 54(3), 30-37. http://pepsic.bvsalud.org/scielo.php?script=sci_arttext\&pid=S0486641X2020000300004\&lng=pt\&tlng=pt.

Chouvier, B. (2004). Les processus psychiques de la médiation. Dunod.

Dunker, C., Perroni, C., Ianinni, G., Rosa, M. D., \& Gurski, R. (Orgs.) (2020). Sonhos confinados: $O$ que sonham os brasileiros em tempos de pandemia. Autêntica.

Emílio, S. A. et al. (2020). El Fotolenguaje en Sesión Grupal Virtual. Revista Psicoanálisis de las Configuraciones Vinculares, XLIII, p. 231-263.

Freud, S. (1987). A Interpretação dos sonhos. In Obras psicológicas completas de Sigmund Freud: edição standard brasileira. $2^{\mathrm{a}}$ ed. Imago. (Original publicado em 1900).

Gui, R. T., \& Coelho, V. L. D. (2013). O Sonhar social: uma experiência no Brasil. Psicologia: Teoria e Pesquisa, 29(4), 459-468. https://doi.org/10.1590/S010237722013000400012

Hazan, G., Knobel, A. M., \& Fernandes, E. (2014). Matriz do Sonhar Social: uma proposta brasileira. Revista Brasileira de Psicodrama, 22(2), 36-44. http://pepsic.bvsalud.org/scielo.php?script=sci_arttext\&pid=S010453932014000200005\&lng=pt\&tlng=pt.

Kaës, R. (2002). La Polyphonie du Rêve. Dunod.

Kaës, R. (2003). A polifonia do sonho e seus dois umbigos: os espaços oníricos comuns e compartilhados. Revista da SPAGESP, 4(4), 1-14. http://pepsic.bvsalud.org/scielo.php?script=sci_arttext\&pid=S1677$29702003000100002 \& \operatorname{lng}=\mathrm{pt} \& \operatorname{tlng}=\mathrm{pt}$

Kaës, R. (2005). Os Espaços Psíquicos Comuns e Partilhados. Transmissão e Negatividade. Casa do Psicólogo.

Kaës, R. (2011). Um Singular Plural: a psicanálise à prova do Grupo. Edições Loyola.

Lawrence, W. G. (Ed.) (1998). Social Dreaming and Work. Karnac.

Lawrence. W. G. (2010). The creativity of social dreaming. Karnac.

Manley, J. (2014). Gordon Lawrence's Social Dreaming Matrix: Background, Origins, History, and Developments. Organisational \& Social Dynamics, 14(2), 322-341.

Penna, C. (2013). O Sonhar Social e o Contar o Sonho: novas vias régias de acesso ao inconsciente? Cadernos de Psicanálise, 35(29), 11-26. http://pepsic.bvsalud.org/scielo.php?script=sci_arttext\&pid=S1413$62952013000200001 \& \operatorname{lng}=\mathrm{pt} \& \operatorname{tlng}=\mathrm{pt}$.

Pereira, A., \& Coelho, N. J. (Org.) (2021). Sonhar. Figurar o terror, sustentar o desejo. Zagodoni.

Pichon-Rivière, E. (1994). O processo grupal. Martins Fontes. (Original publicado em 1980)

Roussilllon, R. (2013). Une métapsychologie de la médiation et du médium malléable. In A. Brun, B. Chouvier, \& R. Roussillon, Manuel des médiations thérapeutiques. Dunod. https://doi.org/10.3917/dunod.chouv.2013.01.0041 
Vacheret, C. (2000). Développement de quelques pistes théoriques. In Photo, Groupe et soin Psychique. PUL.

Vacheret, C. (2008). A Fotolinguagem(C: um método grupal com perspectiva terapêutica ou formativa. Psicologia: Teoria e Prática,10(2), 180-191. http://pepsic.bvsalud.org/scielo.php?script=sci_arttext\&pid=S1516-

$36872008000200014 \& \operatorname{lng}=$ pt\&tlng=pt.

Zerbatto, B. P., \& Prestes, F. S. (2020). As imagens oníricas durante a pandemia Covid19. Revista Cadernos de Psicologia, (1). cadernosdepsicologias.crppr.org.br/edicoes/numero_01_2020.

Recebido: $30 / 08 / 2021$

Reformulado: 02/12/2021

Aceito: $10 / 12 / 2021$

\section{Sobre os autores:}

Pablo Castanho é docente do Departamento de Psicologia Clínica do Instituto de Psicologia da Universidade de São Paulo.

Solange Aparecida Emílio é presidente do NESME (Núcleo de Estudos em Saúde Mental e Psicanálise das Configurações Vinculares) e docente da Pontifícia Universidade Católica de São Paulo.

Victória de Angelis é psicóloga pela Universidade de São Paulo.

Wellington Gomes da Silva é psicólogo pela Universidade de São Paulo.

Mayara Coutinho é doutoranda em Psicologia Clínica pelo Instituto de Psicologia da Universidade de São Paulo.

Correspondência: solange.emilio@terra.com.br 